\title{
Purinergic Signaling in neutrophils during inflammatory diseases
}

Hui Sun1,2 Gang Xu3 Pingsong Li3 Yumei Li1,4 Bingwei Sun5 2221613062@stmail.ujs.edu.cn

diligencesun@hotmail.com

1334759210@qq.com

1000011265@ujs.edu.cn

1000010661@ujs.edu.cn

1. Institute of Regenerative Medicine, Affiliated Hospital of Jiangsu University, Jiangsu University, Zhenjiang 212001, Jiangsu Province, China

2. School of Medicine, Jiangsu University, Zhenjiang, Jiangsu People's Republic of China

3. Department of Burn and Plastic Surgery, Subei People's Hospital of Jiangsu Province, Yangzhou, Jiangsu, People's Republic of China

4. Department of Dermatology, Affiliated Hospital of Jiangsu University, Jiangsu University, Zhenjiang, Jiangsu 212001, China

5. Department of Burns and Plastic Surgery, Suzhou Hospital Affiliated to Nanjing Medical University, Suzhou 215002, Jiangsu Province, China

\begin{abstract}
Purinergic signaling is that nucleotides (especially ATP) and adenosine are utilized as transmitter molecules, which play an important role in the immune system. In the extracellular ventricle, ATP plays a significant role of pro-inflammatory molecules mainly through activating P2 receptors, while adenosine plays the role of anti-inflammatory molecules mainly through activating P1 receptors. As we know, neutrophils are the most abundant immune cells in our circulation and have become an essential part of coordinating a series of complex events during inflammatory diseases. However, due to the destruction of inflammatory substances from neutrophils, the activation of neutrophils is fine-tuned, and purinergic signaling is associated with this process. As a matter of fact, altering the balance between P2 and $\mathrm{P} 1$ signals is of great importance for neutrophils to exert immune activities properly. Here, we review the role of purinergic signaling in regulatory function of neutrophils during inflammatory disease, and then discuss the potential contribution of targeted purinergic signals in the treatment of the neutrophil during inflammatory diseases.
\end{abstract}

Keywords: purinergic signaling, regulatory role, neutrophils, inflammation 


\section{Introduction}

Purinergic signaling is a heterocyclic aromatic molecule, which is one of the oldest and most influential biochemical compounds in the history of evolution(1, 2). Purine nucleotide adenosine triphosphate (ATP) is a universal energy currency for intracellular biological reactions on which mammalian life depends(3). Here, we study the role of purine as an extracellular signal molecule, with special attention to ATP, adenosine diphosphate (ADP) and adenosine. In recent decades, further studies have found various biological effects of ATP, ADP and adenosine signals(4-6). These mediators have a role by activating G-protein coupling or ligand-gated ion channel receptors(2). Adenosine is generated by ATP and ADP through the action of cell surface enzymes, which also express receptors for these mediators(7). Because ATP and ADP receptors and adenosine receptors often play the opposite role, the cellular response is not simply related to the ratio of adenosine concentration, but also to the relative expression level and signal intensity of adenosine receptors $(1,8)$. Purinergic signaling system is a revolutionary selected system that can finetune the function of immune cells(1). In fact, purinergic signals mediated by P2R and P1R often play the opposite role in regulating the function of immune cells(9). Specifically, ATPmediated P2 receptor signal generally promotes the activation of immune cells, while ADOmediated P1R signal mainly limits the activation of immune cells $(2,10)$. The transfer of balance from the pro-inflammatory P2R signal to the anti-inflammatory P1R signal, or vice versa, may have a significant effect on the outcome of the immune response(8).

Neutrophils are the most abundant immune cells in human blood and have been made an important part of coordinating a series of complex events in the process of inflammation(11). However, due to the short lifespan of neutrophils, it is difficult to maintain in vitro culture and genetic manipulation, so it has been largely ignored in the field of purinergic signaling in previous studies(12). Recently, a large amount of pharmacological and genetic evidence has changed this paradigm by expanding the role of purinergic signals in neutrophils(13-15). The coordinated interaction between P2 and P1 purinergic signals can effectively activate the immune activity of neutrophils and restore homeostasis in the tissue(8). Here, we review the evidence of neutrophil purinergic signaling and their role in the mechanism of inflammatory diseases, and emphasize their therapeutic potential in the treatment of neutrophil-related diseases, such as inflammatory bowel disease (IBD), pulmonary inflammation and ischemiareperfusion injury.

\section{Classification of Purinergic receptors}

The first report of purinergic signaling dates back to 1929, when scientists injected heart tissue extracts intravenously into intact animals and observed a temporary slowdown in heart rate; they later confirmed that the biological agent was an "adenine compound"(16). The ATP (P2 receptor) and ADO (P1 receptor) receptor families were first discovered in 1978(17, 18). When nucleotides and nucleosides bind to specific plasma membrane receptors needed for cell-tocell communication, they are called purinergic receptors, which are divided into P2 and P1 receptors, respectively(1). According to their sequence and signal characteristics, G-proteincoupled P1 receptors are further divided into four subtypes (A1, A2A, A2B and A3), while P2 receptors form two groups, including metabolic $\mathrm{G}$-protein-coupled $\mathrm{P} 2 \mathrm{Y}$ receptors and ionic 
P2X receptors. Nucleotides (ATP, ADP, UTP and UDP) formed or released outside the cell bind and activate $\mathrm{P} 2$ receptor, while adenosine, which exists in the extracellular environment, is the agonist of $\mathrm{P} 1$ receptor(2).

\subsection{P1Rs}

P1Rs is a classic G-protein-coupled metabolic receptor, which is a single polypeptide consisted of seven $\alpha$-helices perpendicular to the plasma membrane(19). ADO is the endogenous ligand of all four ADO receptors. A1R and A3R inhibit adenylate cyclone activity through GIG-protein and stimulate phospholipase C / inositol triphosphate / diacylglycerol pathway through $G-\beta$ $~ G$-protein(20). A2AR and A2BR are mainly coupled to Gs G-protein to enhance $A C$ activity. In addition, all four $A D O$ receptors are coupled to mitogen-activated protein kinase (MAPK), which makes them have more complex biological functions(19).

\subsection{P2Rs}

As mentioned previously, P2 receptors form two groups, including metabolic G-proteincoupled P2X receptors and P2Y receptors. P2XRs is an ATP-gated trimer ion channel. P2XRs has a tertiary topology similar to intracellular $\mathrm{NH} 2$ and longer $\mathrm{COOH}$ ends, extracellular macroscopic responsible for ligand binding, and two transmembrane regions (TM1 and TM2)(21). In addition, activation of P2X7R forms a macropore that allows molecules as long as $900 \mathrm{kDa}$ to pass through, which is involved in the release of pro-inflammatory cytokines(2). P2YRs belong to the delta branch of class A G-protein-coupled receptor family, which contains seven hydrophobic transmembrane regions(22). Based on phylogenetic and structural differences, two different P2YR subgroups have been determined(21). $\mathrm{P} 2 \mathrm{Y} 1 / 2 / 4 / 6 / 11 R$ s is mainly coupled with $\mathrm{Gq} / \mathrm{G} 11$, activating phospholipase C/inositol triphosphate/diacylglycerol pathway to increase intracellular calcium, while P2Y12/13/14Rs is mainly coupled with GI/0 to inhibit adenylate cyclase (AC), and reduce intracellular cyclic adenosine monophosphate (CAMP). More evidence suggests that P2Y11R uses Gs to stimulate AC, to increase intracellular CAMP(22).

\section{Release \Signal transduction and Termination of Nucleotide}

\subsection{Extracellular nucleotide release}

In the physiological state, mammalian cells contain a high concentration of ATP (5-8mM), and extracellular ATP exists as a very small amount of $\sim 10 \mathrm{nM}(23)$. However, pathological conditions such as inflammation or ischemia can lead to the release of ATP. Cell necrosis is linked to the outflow of ATP from intracellular storage, and cell necrosis releases a large amount of ATP from the intracellular storage pool. In most cases, the release of extracellular ATP is finely controlled by diffusion through plasma membrane channels or exocytosis of ATP-rich vesicles(24). Connexin and Pannexin half channel are widely reflected in diverse cell types, including neutrophils, endothelial cells and epithelial cells(24).

In extracellular space, ATP and ADP are rapidly metabolized into adenosine monophosphate (AMP), and AMP is metabolized into adenosine. This nucleotide phosphate hydrolysis includes a two-step enzyme process regulated by extracellular enzymes(25). In the first step, both ATP and ADP are transformed into AMP by extracellular nucleoside triphosphate diphosphate hydrolase 1 (CD39)(Figure 1)(1, 26). The subsequent step in the extracellular synthesis of adenosine is the conversion of extracellular AMP to adenosine by extracellular 5-nucleotidase (CD73)(26). In the extracellular environment, the levels of ATP and ADP are strictly controlled 
by plasma membrane extracellular nucleotidase, such as nucleoside triphosphate diphosphate hydrolase 1 (NTPDase1, also known as CD39) and extracellular-5-phosphatenucleotidase (also known as CD73), which convert ATP/ADP to AMP, and then AMP to ADO, respectively(26). The CD39/CD73 pathway is a key checkpoint that promotes the transition from ATP-induced pro-inflammatory environment to ADO-induced anti-inflammatory environment $(27,28)$. Both CD39 and CD73 are expressed in neutrophils and seem to play a key role in regulating neutrophil activation(29). In addition to CD39 and CD73, nucleotide pyrophosphatase and phosphodiesterase (NPPs), alkaline phosphatase (ALP), acid phosphatase (ACP) and extracellular kinases can also degrade extracellular nucleotides and nucleosides(2).

\subsection{Extracellular adenosine signal transduction}

Adenosine can signal through four distinct $G$ protein-coupled receptors: adenosine $A 1$ receptor (ADORA1), adenosine $A 2 A$ receptor (ADORA2A), adenosine $A 2 B$ receptor (ADORA2B) and adenosine A3 receptor (ADORA3)(30-32). Each adenosine receptor subtype is distributed differently on each adenosine target cell. For example, ADORA2B is highly reflected in vascular endothelial cells, while ADORA2A is highly expressed in immune cells, such as neutrophils and lymphocytes(33, 34). The specific human disease state associated with defects or mutations in any of the four defined adenosine receptors is unclear. Adenosine receptor gene knockout mice are alive, indicating that the system is redundant under physiological conditions(35). More than twenty years ago, burn stock described the existence of the ATP receptor, which he called the "P2" receptor(36). Then, according to the chemical properties, it is split into a P2X receptor (ligand gated ion channel) and P2Y receptor (G protein coupled receptor)(37). Targeted mice with P2 receptor deletion usually survive, indicating that the signal system is redundant under physiological conditions(38). However, P2 receptor gene knockout mice can be free from inflammatory diseases under pathological conditions such as asthma, vascular inflammation or graft-versus-host disease(39). Genomic studies have directly shown that ATP signal is related to human inflammatory or tumor diseases(40). For instance, in chromosomal studies involving humans, mutations in the P2X7 receptor gene are associated with susceptibility to tuberculosis and clinical outcomes of chronic lymphoblastic leukemia(41), and genetic abnormalities of T-cell-dependent P2Y11 signals are associated with paroxysmal narcolepsy(42, 43). On the contrary, under pathological conditions, many specific biological and cell-specific functions of each receptor have been determined. The chronotropic effect of adenosine, which plays a crucial role in the treatment of supraventricular tachycardia, depends on ADORA. Pharmacological studies have shown that ADORA2A signal plays an anti-inflammatory function in human neutrophils, ADORA2A plays a key role in reducing the activation of inflammatory cells in many tissue sites, ADORA2A antagonists have a therapeutic effect on Parkinson's disease(44), and ADORA2B plays a role in tissue adaptation to hypoxia, inflammation or ischemia(45-47).

\subsection{Termination of adenosine signal}

In the process of signal termination, adenosine is transported from the extracellular space to the intracellular space. This transport involves balancing nucleoside transporters-diffusionlimited channels, allowing adenosine to pass freely through the cell membrane depending on its concentration gradient(48). Mice with balanced nucleoside transporter gene deletion survived, but their adenosine levels increased during disease, which assists in the protection 
of them during organ ischemia. Dipyridamole can be utilized to induce coronary artery vasodilation by inhibiting balanced nucleoside transporter and increasing the volume of extracellular adenosine. In cells, adenosine is quickly metabolized to inosine by adenosine deaminase (ADA), or to AMP by adenosine kinase(Figure 1)(1, 49).

\section{Regulation of purinergic receptors on neutrophil function}

\section{Expression of purinergic receptors in neutrophils}

The expression of all purinergic receptors except P2Y12R has been analyzed(50). Convincing data from mRNA, protein and functional analysis show that P2X1R, P2X7R, P2Y2R, P2Y14R and all four ADO receptors are taken into account in neutrophils(4). The evidence for the expression of other purinergic receptors is relatively weak, and further studies are needed to confirm whether neutrophils express P2X2-6RS, P2Y1R, P2Y4R, P2Y6R, P2Y11R, P2Y12R and P2Y13R(4, 14, 51).

\subsection{Purinergic signaling can regulate neutrophil phagocytosis and neutrophil extracellular trap (NET)}

Neutrophils are professional phagocytes with a unique phagocytic ability to remove pathogens and cell fragments(12). The discovery of NET expands the understanding of neutrophil antimicrobial strategies(52). The net is a large extracellular reticular structure composed of discontented chromatin and neutrophil antimicrobial factors. The network can not only collect and kill various microorganisms, but also activate and regulate innate immunity and acquired immunity(53). Both phagocytosis and Net are essential for neutrophils to effectively eliminate invasive pathogens. However, when P2X1R antagonist was introduced, the promoting effect of LPS was removed(14). These results suggest that autocrine activation of P2 signal may be the key to enhance the phagocytic function of neutrophils due to the release of extracellular ATP, by neutrophils induced by LPS(4). UDP is the natural ligand of P2Y6R(54). Although UDP itself can not initiate the network formation of human neutrophils, the P2Y6 signal mediated by UDP is involved in the formation of Net induced by sodium urate crystals(55). Neutrophil A3R enhances bacterial clearance and activates human neutrophils with $A 3 R$ agonists to promote the formation of filamentous processes of neutrophils, which are recognized as cell lines $(55,56)$.

\subsection{Purinergic signaling can regulate neutrophil chemotaxis}

Chemotaxis is the capacity of cells to sense gradient, polarization and directional migration in the chemotactic gradient field(4). Recent studies have shown that autocrine purinergic signals play a key role in guiding neutrophil chemotaxis $(4,57)$. In the process of chemotaxis, neutrophils need to be polarized, with an anterior pseudopod at the anterior edge of sense the gradient of chemical attraction and a posterior pseudopod at the posterior edge to maintain directional migration(57). Once neutrophils sense the chemical inducer Panx1 half channel quickly shifts to the anterior edge and releases mitochondrial-derived ATP from the pseudopodia(58, 59). The extracellular release of ATP acts as an autocrine messenger, amplifying chemotactic signals by activating P2Y2R-mediated frontal mTOR signals(60). The mechanism of neutrophil gradient sensing is constituted by extracellular ATP and positive feedback of P2Y2R receptor(61). Then, the released ATP is hydrolyzed into ADO, in the CD73 associated with the neutrophil membrane in situ, and then the frontal neutrophil A3R is activated to drive the second round of signal amplification. The subsequent step amplification 
is also essential for promoting the initial expansion of neutrophil chemotaxis because it controls the rate of migration. At the trailing edge, diffuse or locally produced ADO activates A2AR and triggers cAMP/PKA signals to suppress P2Y2R-mediated mTOR signals(61). Activation of A2AR maintains cellular polarization and promotes the contraction of the tail pods.

43 Purinergic signaling can regulate the rolling, adhesion and migration of neutrophils Neutrophils are usually the primary immune cells recruited to the inflammatory site(12). In most tissues, the neutrophil recruitment cascade includes the following recognized steps: lineage, rolling, adhesion, crawling, and subsequent outcome(62). A recent in vivo study showed that there was not any difference in lipopolysaccharide-induced neutrophil rolling and adhesion between WT and P2rx1-/-mice. However, neutrophil migration in P2rx1-/mice was inhibited, suggesting that P2 signaling may be associated with neutrophil recruitment cascades by promoting neutrophil migration rather than rolling and adhesion(63). The adoptive transfer of neutrophils from WT and P2rx1-/-mice to WT mice showed that the loss of P2X1R in neutrophils rather than the loss of P2X1R in vascular endothelial cells or other immune cells caused neutrophils to migrate from venules. In contrast to P2X1R, A2AR expressed by neutrophils appears to inhibit the recruitment cascade of neutrophils. Using A2AR agonist to activate A2AR signal, tumor necrosis factor-2 integrin-mediated neutrophil rolling and adhesion were significantly inhibited in $\beta$ - $\alpha$-attacked mouse epidermal muscle retroactively venule and in vitro flow chamber model(63).

\subsection{Purinergic signaling can regulate neutrophil degranulation}

Neutrophil granules, including primary granule (PGs), secondary granule (SGS), tertiary granule (TGS) and SVS, are formed successively during granulogenesis(64). Neutrophil granules contain a large number of antimicrobial peptides and proteolytic enzymes $(64,65)$. These proteins enable neutrophils to exert bactericidal and immune functions, but if they are not released properly, they are potentially harmful to the host. Purinergic signals play a bidirectional role in regulating neutrophil degranulation. An in vitro study showed that ATP y S, a unhydrolyzable adenosine triphosphate analogue, could further enhance fMLP-induced neutrophil degranulation, but hydrolyzable adenosine triphosphate could not further promote fMLP-induced neutrophil degranulation. On the contrary, ATP can be hydrolyzed to inhibit fMLP-induced neutrophil degranulation(66). Considering the strong hydrolytic activity of extracellular nucleotidase on neutrophil membrane to convert ATP into ADO, further studies have demonstrated that this inhibitory effect on neutrophil degranulation is induced by the hydrolysate of ATP and ADO(66). In addition, with the use of selective agonists and antagonists, a recent study has demonstrated that LPS-induced ATP autocrine promotes neutrophil exocytosis to SVS, TGS and SGS by activating P2X1R. The described two-way effect of purinergic signals on neutrophil degranulation may be necessary for neutrophils to properly release their granule contents to regulate their antibacterial activity during infection and to avoid damage to healthy tissue(66).

\subsection{Purinergic signaling can regulate the oxidative burst of neutrophils}

Superoxide is only an effective antimicrobial agent, which can kill microbial pathogens and regulate a variety of signal pathways(67). Owing to the destructiveness of superoxide, the oxidation burst is fine-tuned, and the purine energy signal is closely connected with this process. P2Y2R is the activator of neutrophil oxidative burst. The down-regulation of P2Y2R 
expression in differentiated neutrophil-like HL-60 cells (DHL-60) can dramatically inhibit the oxidative burst induced by fMLP. Sodium urate crystals can induce oxidative burst of neutrophils, but the antagonist of P2Y6R can inhibit the oxidative burst of neutrophils induced by sodium urate crystals(54). It is useful to noting that the absence of autocrine activation of P2Y2R and P2Y6R in exogenous ATP, neutrophils in these two studies may amplify oxidative bursts. Compared with P2Y2R and P2Y6R, A2BR and A3R inhibited the oxidative burst of neutrophils(68).

\subsection{Purinergic signaling can regulate neutrophil apoptosis}

The circulating neutrophils is under a short lifespan of only 20 hours and will not proliferate. However, the lifespan of neutrophils is markedly prolonged under inflammation and other pathological conditions(69). Extracellular ATP is a major regulator of neutrophil apoptosis. Even exposure to ATP for 10 minutes is sufficient to cause a persistent delay in human neutrophil apoptosis. Utilizing various selective purine receptor antagonists, researchers have verified that ATP-mediated delay in neutrophil apoptosis is P2Y11R-dependent. P2Y11R mediates the anti-apoptosis effect of ATP by elevating CAMP in neutrophils and activating subsequent cAMP-dependent protein kinases(70).

\section{Neutrophil-related Infectious and Inflammatory Diseases}

\subsection{Purinergic signaling of neutrophils in Inflammatory Bowel Disease}

Inflammatory bowel disease is linked to excessive intestinal inflammation, and purine signal is related to inflammatory bowel disease. Intestinal inflammation is related to the profound changes of metabolic supply and demand, which leads to the deep hypoxia of inflammatory mucosa(71). Effective immune response depends on the effective activation of neutrophils(72). Neutrophils release extracellular ATP under the action of inflammatory mediators. Neutrophils may reduce key immune responses, such as cell adhesion and chemotaxis, partly due to changes in the expression of purinergic signal-related genes mRNA(4). Studies have shown that hypoxia signals are transcribed to induce CD39 and CD73(73). During intestinal inflammation, thus transferring the balance from ATP signals to adenosine signals. In addition, pharmacological studies in mice have shown that HIF activator can reduce intestinal inflammation(73). The ATP signal of neutrophils is associated with long-term duodenal motility disturbance and intestinal nerve injury in IBD, which is consistent with the proinflammatory effect of P2 receptor signal in this disease(74). P2X7, pAnnexin-1 channel, ASC adaptor protein and caspases are all involved in ATP-induced signaling pathways that drive intestinal nerve death during enteritis. In addition, a subset of $C D 4+T$ lymphocytes of regulatory $T$ cells needs extracellular adenosine production dependent on CD39 and CD73 to inhibit experimental enteritis in order to comply with its inhibitory function in mouse models, and neutrophils strengthen the inhibitory function in this process. Generally speaking, in mouse models, $\operatorname{CD} 39$ or $\operatorname{CD} 73(75,76)$. Adenosine receptor signaling appears to be antiinflammatory and barrier protective effects in experimentally induced colonic inflammation through adenosine signaling events involving Adora2a or Adora2b receptors(77). In addition, sulfadiazine and methotrexate-two commonly used drugs-are utilized to treat the antiinflammatory effects of IBD involving the release of extracellular adenosine. Taken together, these findings highlight the therapeutic potential of anti-inflammatory drug strategies that balance the pro-inflammatory activation of $\mathrm{P} 2$ receptors to adenosine receptors, especially 
Adora2a and Adora2b, in the treatment of $\operatorname{IBD}(78,79)$. For instance, this conversion can be done through the use of HIF to achieve adenosine receptor agonists, soluble forms of apyrase (converting ATP and ADP to AMP) or extracellular nucleotidase (converting AMP to adenosine) or adenosine receptor agonists.

\subsection{Purinergic signaling of neutrophils in Acute Lung injury}

Acute lung injury is part of the main causes of morbidity and mortality associated with acute diseases(80). Massive neutrophil infiltration is a sign of acute lung injury and exposure to lung injury increases the level of ATP in the lung, indicating that activation of P2 receptors such as P2Y6 or P2X7 leads to increased inflammation and vascular leakage $(81,82)$. Some genetic and pharmacological studies have confirmed that inappropriate activation of P2R signal is related to neutrophil-induced inflammation and tissue damage. Knockout or antagonism of mouse P2X7R can inhibit neutrophil recruitment into the lung and protect ALI(83). LPS provides dual signals for alveolar macrophages, induces the production of cytokines through TLR4/MYD88 signals, induces cytokine necrosis through P2X7R/CD14 signals, promotes the release of pre-IL-1 $\alpha$, then activates IL-1 receptors on endothelial cells, induces tight junctions to open, and makes neutrophils infiltrate into the lungs $(84,85)$. In addition, P2X7R-induced soluble VCAM-1 exfoliated from type I alveolar epithelial cells and used as a chemoattractant to recruit neutrophils during ALI(86). Intratracheal LPS-induced pulmonary neutrophil recruitment was also inhibited in mice treated with P2Y1R or P2Y14R antagonists. In the ALI model induced by severe pulmonary infection, P2X7R is associated with the aggravation of inflammatory injury and neutrophil infiltration. When mice are infected with the highly virulent Mycobacterium bovis, it can cause severe tuberculosis and lung damage. The lung injury of chimeric mice with P2X7R deletion in bone marrow-derived cells was substantially alleviated, indicating that P2X7R in bone marrow-derived cells played an important role in the occurrence and development of severe tuberculosis(87). Increased immune response is one of the principal causes of lung injury during influenza virus infection. P2X7R gene knockout led to better results for influenza virus infection, characterized by reduced lung pathology and neutrophil infiltration. In addition, deletion of P2X7R or inhibition of P2X7R activation by selective antagonists or apyrase can inhibit pulmonary inflammation and neutrophil infiltration in the early stage of acute adenovirus infection(88). Cecal ligation and puncture (CLP) is another method to induce SIRS-related ALI. CLP, in P2ry2-/-and Adora3-/-mice the researchers observed a decrease in neutrophil recruitment in the lungs and a decrease in ALI progress compared with WT mice. P2Y12R antagonists can successfully reverse the pathological changes of WT mice. Similar results have been observed in P2y12-/-mice, and P2Y12R antagonists can successfully reverse the pathological changes of WT mice. These studies upheld the role of $\mathrm{P} 2 \mathrm{Y} 2 \mathrm{R}, \mathrm{A} 3 \mathrm{R}$ and $\mathrm{P} 2 \mathrm{Y} 12 \mathrm{R}$ in promoting neutrophil infiltration during $\operatorname{ALI}(89,90)$.

\subsection{Purinergic signaling of neutrophils in Ischemia-reperfusion injury}

Ischemia-reperfusion injury occurs after initial ischemia or hypoxia, with the return of blood and accompanying oxygen to tissue, which is a common complication of myocardial infarction, transplantation, stroke and trauma(91, 92). Neutrophil infiltration is a sign of IR injury and is an important part of protracted inflammatory response and its severity. It has been confirmed that purinergic signal has a profound effect on neutrophils during IR injury (93). In a variety of experimental animals, the application of A2AR agonists has achieved beneficial effects in 
inhibiting neutrophil infiltration and concomitant neutrophil infiltration in kidney, lung and myocardial IR injury(94). Further through-hole analysis in vitro showed that A3R agonists could inhibit the migration of neutrophils, suggesting that the protective effect of $A 3 R$ may be explained by the direct inhibition of neutrophil activation(95). In addition, A3R activation decreased neutrophil infiltration in IR-injured myocardium in WT mice, but not in global $A 3 R$ deficient or chimeric mice lacking A3R in BM-derived cells. Subsequent experimental results are consistent with previous studies, indicating that A3R expressed by neutrophils is essential for the inhibition of neutrophil infiltration(95).

Distinct from the inhibitory effect of $A 1 R, A 2 A R$ and $A 3 R$ on neutrophil activation during IR injury, A2BR plays a bi-directional role in myocardial and lung IR injury(96). However, according to data obtained from BM chimeric mice, the pro-inflammatory effect of A2BR may be specific to resident lung cells, but not to BM-derived neutrophils(96). A recent report showed that the antagonistic effect of P2X7R could improve renal neutrophil infiltration and tissue damage induced by IR, while P2X7R gene knockout achieved comparable results. Chimeric mice with bone marrow-derived cell P2X7R deficiency further confirmed that the activation of P2X7R in bone marrow-derived cells is required for renal neutrophil infiltration during IR injury $(97,98)$. The effects of other $P 2$ receptors on neutrophils during IR injury have yet to be studied.

\section{Conclusion}

Purinergic signal transduction is a major regulatory mechanism in various inflammatory diseases. Significant progress has been made in identifying various types of neutrophil purinergic receptors and understanding their function in coordinating the appropriate immune response to invasive pathogens or diseased tissues. The fine-tuning balance between P2R and P1R signals seems to be indispensable for the formation of neutrophil plasticity and heterogeneity to coordinate a series of complex events during inflammation. Several drugs that target purinergic signals, such as adenosine and cuspidate, have been used in patients. In the near future, the research progress in the field of neutrophil purinergic signal transduction may be further used in the treatment of inflammatory or infectious diseases, and the continuous development of this field will open up several new ways for the treatment of patients with inflammatory diseases.

\section{Reference}

1. Eltzschig HK, Sitkovsky MV, Robson SC. Purinergic signaling during inflammation. N Eng/ J Med (2012) 367(24):2322-33. doi: 10.1056/NEJMra1205750. PubMed PMID: 23234515.

2. Idzko M, Ferrari D, Eltzschig HK. Nucleotide signalling during inflammation. Nature (2014) 509(7500):310-7. doi: 10.1038/nature13085. PubMed PMID: 24828189.

3. Menzies RI, Tam FW, Unwin RJ, Bailey MA. Purinergic signaling in kidney disease. Kidney Int (2017) 91(2):315-23. Epub 2016/10/22. doi: 10.1016/j.kint.2016.08.029. PubMed PMID: 27780585. 4. Wang $X$, Qin $W, X u X$, Xiong $Y$, Zhang $Y$, Zhang $H$, et al. Endotoxin-induced autocrine ATP signaling inhibits neutrophil chemotaxis through enhancing myosin light chain phosphorylation. Proc Natl Acad Sci U S A (2017) 114(17):4483-8. Epub 2017/04/10. doi: 10.1073/pnas.1616752114. PubMed PMID: 28396412.

5. Caiazzo E, Bilancia R, Rossi A, lalenti A, Cicala C. Ectonucleoside Triphosphate Diphosphohydrolase-1/CD39 Affects the Response to ADP of Female Rat Platelets. Front 
Pharmacol(2020) 10:1689-. doi: 10.3389/fphar.2019.01689. PubMed PMID: 32082171.

6. Nomata J, Terauchi K, Fujita Y. Stoichiometry of ATP hydrolysis and chlorophyllide formation of dark-operative protochlorophyllide oxidoreductase from Rhodobacter capsulatus. Biochem Biophys Res Commun (2016) 470(3):704-9. Epub 2016/01/13. doi: 10.1016/j.bbrc.2016.01.070. PubMed PMID: 26774340.

7. Firouzmand S, Ajori L, Towse J, Allameh F, Najafi S, Javed S, et al. Investigating the associations of mucosal P2Y6 receptor expression and urinary ATP and ADP concentrations, with symptoms of overactive bladder. Neurourol Urodyn (2020):10.1002/nau.24322. doi: 10.1002/nau.24322. PubMed PMID: 32049380.

8. Lin SCY, Thorne PR, Housley GD, Vlajkovic SM. Purinergic Signaling and Aminoglycoside Ototoxicity: The Opposing Roles of P1 (Adenosine) and P2 (ATP) Receptors on Cochlear Hair Cell Survival. Front Cell Neurosci (2019) 13:207-. doi: 10.3389/fncel.2019.00207. PubMed PMID: 31156393.

9. Przybyła T, Sakowicz-Burkiewicz M, Pawełczyk T. Purinergic signaling in B cells. Acta Biochim Pol(2018) 65(1):1-7. Epub 2018/01/23. doi: 10.18388/abp.2017_1588. PubMed PMID: 29360885.

10. Shi L, Yang L, Wu Z, Xu W, Song J, Guan W. Adenosine signaling: Next checkpoint for gastric cancer immunotherapy? Int Immunopharmacol (2018) 63:58-65. Epub 2018/07/31. doi: 10.1016/j.intimp.2018.07.023. PubMed PMID: 30075429.

11. Ng LG, Ostuni R, Hidalgo A. Heterogeneity of neutrophils. Nat Rev Immuno/(2019) 19(4):25565. doi: 10.1038/s41577-019-0141-8. PubMed PMID: 30816340.

12. Silvestre-Roig C, Hidalgo A, Soehnlein O. Neutrophil heterogeneity: implications for homeostasis and pathogenesis. Blood (2016) 127(18):2173-81. Epub 2016/03/21. doi: 10.1182/blood-2016-01-688887. PubMed PMID: 27002116.

13. Patel S, Fu S, Mastio J, Dominguez GA, Purohit A, Kossenkov A, et al. Unique pattern of neutrophil migration and function during tumor progression. Nat Immuno/(2018) 19(11):1236-47. Epub 2018/10/15. doi: 10.1038/s41590-018-0229-5. PubMed PMID: 30323345.

14. Karmakar M, Katsnelson MA, Dubyak GR, Pearlman E. Neutrophil P2X7 receptors mediate NLRP3 inflammasome-dependent IL-1 $\beta$ secretion in response to ATP. Nat Commun (2016) 7:10555-. doi: 10.1038/ncomms10555. PubMed PMID: 26877061.

15. Corps KN, Roth TL, McGavern DB. Inflammation and neuroprotection in traumatic brain injury. JAMA Neurol(2015) 72(3):355-62. doi: 10.1001/jamaneurol.2014.3558. PubMed PMID: 25599342. 16. Drury AN, Szent-Györgyi A. The physiological activity of adenine compounds with especial reference to their action upon the mammalian heart. J Physiol (1929) 68(3):213-37. doi: 10.1113/jphysiol.1929.sp002608. PubMed PMID: 16994064.

17. de Andrade Mello P, Coutinho-Silva R, Savio LEB. Multifaceted Effects of Extracellular Adenosine Triphosphate and Adenosine in the Tumor-Host Interaction and Therapeutic Perspectives. Front Immunol (2017) 8:1526-. doi: 10.3389/fimmu.2017.01526. PubMed PMID: 29184552.

18. Ferrari D, Gambari R, Idzko M, Müller T, Albanesi C, Pastore S, et al. Purinergic signaling in scarring. FASEB J(2016) 30(1):3-12. Epub 2015/09/02. doi: 10.1096/fj.15-274563. PubMed PMID: 26333425.

19. Jespers W, Schiedel AC, Heitman LH, Cooke RM, Kleene L, van Westen GJP, et al. Structural Mapping of Adenosine Receptor Mutations: Ligand Binding and Signaling Mechanisms. Trends Pharmacol Sci (2018) 39(1):75-89. Epub 2017/12/05. doi: 10.1016/j.tips.2017.11.001. PubMed 
PMID: 29203139.

20. Antonioli L, Blandizzi C, Pacher P, Haskó G. Immunity, inflammation and cancer: a leading role for adenosine. Nat Rev Cancer (2013) 13(12):842-57. Epub 2013/11/14. doi: 10.1038/nrc3613. PubMed PMID: 24226193.

21. Jacobson KA, Müller CE. Medicinal chemistry of adenosine, P2Y and P2X receptors. Neuropharmacology (2016) 104:31-49. Epub 2015/12/12. doi: 10.1016/j.neuropharm.2015.12.001. PubMed PMID: 26686393.

22. Zhang K, Zhang J, Gao Z-G, Zhang D, Zhu L, Han GW, et al. Structure of the human P2Y12 receptor in complex with an antithrombotic drug. Nature (2014) 509(7498):115-8. Epub 2014/03/23. doi: 10.1038/nature13083. PubMed PMID: 24670650.

23. Baron L, Gombault A, Fanny M, Villeret B, Savigny F, Guillou N, et al. The NLRP3 inflammasome is activated by nanoparticles through ATP, ADP and adenosine. Cell Death Dis (2015) 6(2):e1629-e. doi: 10.1038/cddis.2014.576. PubMed PMID: 25654762.

24. Morciano G, Sarti AC, Marchi S, Missiroli S, Falzoni S, Raffaghello L, et al. Use of luciferase probes to measure ATP in living cells and animals. Nat Protoc (2017) 12(8):1542-62. Epub 2017/07/06. doi: 10.1038/nprot.2017.052. PubMed PMID: 28683062.

25. Nakano S, Shimizu M, Dinh H, Morii T. Highly selective dual sensing of ATP and ADP using fluorescent ribonucleopeptide sensors. Chem Commun (Camb) (2019) 55(11):1611-4. doi: 10.1039/c8cc09934k. PubMed PMID: 30657140.

26. Antonioli L, Pacher P, Vizi ES, Haskó G. CD39 and CD73 in immunity and inflammation. Trends Mol Med (2013) 19(6):355-67. Epub 2013/04/17. doi: 10.1016/j.molmed.2013.03.005. PubMed PMID: 23601906.

27. Perrot I, Michaud H-A, Giraudon-Paoli M, Augier S, Docquier A, Gros L, et al. Blocking Antibodies Targeting the CD39/CD73 Immunosuppressive Pathway Unleash Immune Responses in Combination Cancer Therapies. Cell Rep (2019) 27(8):2411-25.e9. doi: 10.1016/j.celrep.2019.04.091. PubMed PMID: 31116985.

28. Eckle T, Füllbier L, Wehrmann M, Khoury J, Mittelbronn M, Ibla J, et al. Identification of ectonucleotidases CD39 and CD73 in innate protection during acute lung injury. $J / \mathrm{mmuno/(2007)}$ 178(12):8127-37. doi: 10.4049/jimmunol.178.12.8127. PubMed PMID: 17548651.

29. Reutershan J, Vollmer I, Stark S, Wagner R, Ngamsri K-C, Eltzschig HK. Adenosine and inflammation: CD39 and CD73 are critical mediators in LPS-induced PMN trafficking into the lungs. FASEB J (2009) 23(2):473-82. Epub 2008/10/06. doi: 10.1096/fj.08-119701. PubMed PMID: 18838482.

30. Eltzschig HK. Adenosine: an old drug newly discovered. Anesthesiology (2009) 111(4):904-15. doi: 10.1097/ALN.0b013e3181b060f2. PubMed PMID: 19741501.

31. Greene RW, Bjorness TE, Suzuki A. The adenosine-mediated, neuronal-glial, homeostatic sleep response. Curr Opin Neurobiol (2017) 44:236-42. Epub 2017/06/19. doi: 10.1016/j.conb.2017.05.015. PubMed PMID: 28633050.

32. Haskó G, Linden J, Cronstein B, Pacher P. Adenosine receptors: therapeutic aspects for inflammatory and immune diseases. Nat Rev Drug Discov (2008) 7(9):759-70. doi: 10.1038/nrd2638. PubMed PMID: 18758473.

33. Grenz A, Osswald H, Eckle T, Yang D, Zhang H, Tran ZV, et al. The reno-vascular A2B adenosine receptor protects the kidney from ischemia. PLoS Med (2008) 5(6):e137-e. doi: 10.1371/journal.pmed.0050137. PubMed PMID: 18578565. 
34. Wallace $\mathrm{KL}$, Linden J. Adenosine A2A receptors induced on iNKT and NK cells reduce pulmonary inflammation and injury in mice with sickle cell disease. Blood (2010) 116(23):5010-20. Epub 2010/08/26. doi: 10.1182/blood-2010-06-290643. PubMed PMID: 20798237.

35. Kjaergaard J, Hatfield S, Jones G, Ohta A, Sitkovsky M. A(2A) Adenosine Receptor Gene Deletion or Synthetic A(2A) Antagonist Liberate Tumor-Reactive CD8(+) T Cells from TumorInduced Immunosuppression. J Immunol (2018) 201(2):782-91. Epub 2018/05/25. doi: 10.4049/jimmunol.1700850. PubMed PMID: 29802128.

36. Surprenant A, Rassendren F, Kawashima E, North RA, Buell G. The cytolytic P2Z receptor for extracellular ATP identified as a P2X receptor (P2X7). Science (1996) 272(5262):735-8. doi: 10.1126/science.272.5262.735. PubMed PMID: 8614837.

37. Bavan S, Straub VA, Blaxter ML, Ennion SJ. A P2X receptor from the tardigrade species Hypsibius dujardini with fast kinetics and sensitivity to zinc and copper. BMC Evol Bio/(2009) 9:17doi: 10.1186/1471-2148-9-17. PubMed PMID: 19154569.

38. Wildman SSP, Marks J, Turner CM, Yew-Booth L, Peppiatt-Wildman CM, King BF, et al. Sodium-dependent regulation of renal amiloride-sensitive currents by apical P2 receptors. J Am Soc Nephrol (2008) 19(4):731-42. Epub 2008/01/30. doi: 10.1681/ASN.2007040443. PubMed PMID: 18235098.

39. Burnstock G. Pathophysiology and therapeutic potential of purinergic signaling. Pharmaco/ Rev (2006) 58(1):58-86. doi: 10.1124/pr.58.1.5. PubMed PMID: 16507883.

40. Sridharan S, Kurzawa N, Werner T, Günthner I, Helm D, Huber W, et al. Proteome-wide solubility and thermal stability profiling reveals distinct regulatory roles for ATP. Nat Commun (2019) 10(1):1155-. doi: 10.1038/s41467-019-09107-y. PubMed PMID: 30858367.

41. Sharma AK, Laubach VE, Ramos SI, Zhao Y, Stukenborg G, Linden J, et al. Adenosine A2A receptor activation on $\mathrm{CD} 4+\mathrm{T}$ lymphocytes and neutrophils attenuates lung ischemia-reperfusion injury. J Thorac Cardiovasc Surg (2010) 139(2):474-82. Epub 2009/11/11. doi: 10.1016/j.jtcvs.2009.08.033. PubMed PMID: 19909990.

42. Thunberg U, Tobin G, Johnson A, Söderberg O, Padyukov L, Hultdin M, et al. Polymorphism in the P2X7 receptor gene and survival in chronic lymphocytic leukaemia. Lancet (2002) 360(9349):1935-9. doi: 10.1016/S0140-6736(02)11917-9. PubMed PMID: 12493261.

43. Kornum BR, Kawashima M, Faraco J, Lin L, Rico TJ, Hesselson S, et al. Common variants in P2RY11 are associated with narcolepsy. Nat Genet (2011) 43(1):66-71. Epub 2010/12/19. doi: 10.1038/ng.734. PubMed PMID: 21170044.

44. Welsh TG, Kucenas S. Purinergic signaling in oligodendrocyte development and function. J Neurochem (2018) 145(1):6-18. Epub 2018/03/25. doi: 10.1111/jnc.14315. PubMed PMID: 29377124.

45. Philip K, Mills TW, Davies J, Chen N-Y, Karmouty-Quintana H, Luo F, et al. HIF1A up-regulates the ADORA2B receptor on alternatively activated macrophages and contributes to pulmonary fibrosis. FASEB J (2017) 31(11):4745-58. Epub 2017/07/12. doi: 10.1096/fj.201700219R. PubMed PMID: 28701304.

46. Seo S-w, Koeppen M, Bonney S, Gobel M, Thayer M, Harter PN, et al. Differential TissueSpecific Function of Adora2b in Cardioprotection. J Immunol (2015) 195(4):1732-43. Epub 2015/07/01. doi: 10.4049/jimmunol.1402288. PubMed PMID: 26136425.

47. Eltzschig HK, Faigle M, Knapp S, Karhausen J, Ibla J, Rosenberger P, et al. Endothelial catabolism of extracellular adenosine during hypoxia: the role of surface adenosine deaminase 
and CD26. Blood (2006) 108(5):1602-10. Epub 2006/05/02. doi: 10.1182/blood-2006-02-001016. PubMed PMID: 16670267.

48. Grenz A, Bauerle JD, Dalton JH, Ridyard D, Badulak A, Tak E, et al. Equilibrative nucleoside transporter 1 (ENT1) regulates postischemic blood flow during acute kidney injury in mice. $J$ Clin Invest (2017) 127(6):2438-. Epub 2017/06/01. doi: 10.1172/JCI94890. PubMed PMID: 28569735. 49. Foster CJ, Prosser DM, Agans JM, Zhai Y, Smith MD, Lachowicz JE, et al. Molecular identification and characterization of the platelet ADP receptor targeted by thienopyridine antithrombotic drugs. J Clin Invest (2001) 107(12):1591-8. doi: 10.1172/JCI12242. PubMed PMID: 11413167.

50. Darbousset R, Delierneux C, Mezouar S, Hego A, Lecut C, Guillaumat I, et al. P2X1 expressed on polymorphonuclear neutrophils and platelets is required for thrombosis in mice. Blood (2014) 124(16):2575-85. Epub 2014/08/22. doi: 10.1182/blood-2014-04-571679. PubMed PMID: 25150292.

51. Barrett MO, Sesma JI, Ball CB, Jayasekara PS, Jacobson KA, Lazarowski ER, et al. A selective high-affinity antagonist of the P2Y14 receptor inhibits UDP-glucose-stimulated chemotaxis of human neutrophils. Mol Pharmacol (2013) 84(1):41-9. Epub 2013/04/16. doi: 10.1124/mol.113.085654. PubMed PMID: 23592514.

52. Manfredi AA, Ramirez GA, Rovere-Querini P, Maugeri N. The Neutrophil's Choice: Phagocytose vs Make Neutrophil Extracellular Traps. Front Immunol (2018) 9:288-. doi: 10.3389/fimmu.2018.00288. PubMed PMID: 29515586.

53. Papayannopoulos V. Neutrophil extracellular traps in immunity and disease. Nat Rev Immuno/ (2018) 18(2):134-47. Epub 2017/10/09. doi: 10.1038/nri.2017.105. PubMed PMID: 28990587.

54. Sil P, Hayes CP, Reaves BJ, Breen P, Quinn S, Sokolove J, et al. P2Y6 Receptor Antagonist MRS2578 Inhibits Neutrophil Activation and Aggregated Neutrophil Extracellular Trap Formation Induced by Gout-Associated Monosodium Urate Crystals. J Immuno/ (2017) 198(1):428-42. Epub 2016/11/30. doi: 10.4049/jimmunol.1600766. PubMed PMID: 27903742.

55. Bou Ghanem EN. mSphere of Influence: Adenosine in Host Defense against Bacterial Pneumonia-Friend or Foe? mSphere (2019) 4(4):e00326-19. doi: 10.1128/mSphere.00326-19. PubMed PMID: 31292232.

56. Corriden R, Self T, Akong-Moore K, Nizet V, Kellam B, Briddon SJ, et al. Adenosine-A3 receptors in neutrophil microdomains promote the formation of bacteria-tethering cytonemes. EMBO Rep (2013) 14(8):726-32. Epub 2013/07/02. doi: 10.1038/embor.2013.89. PubMed PMID: 23817552.

57. Tweedy L, Knecht DA, Mackay GM, Insall RH. Self-Generated Chemoattractant Gradients: Attractant Depletion Extends the Range and Robustness of Chemotaxis. PLOS Biol (2016) 14(3):e1002404-e. doi: 10.1371/journal.pbio.1002404. PubMed PMID: 26981861.

58. Weninger W, Biro M, Jain R. Leukocyte migration in the interstitial space of non-lymphoid organs. Nat Rev Immunol (2014) 14(4):232-46. Epub 2014/03/07. doi: 10.1038/nri3641. PubMed PMID: 24603165.

59. Rhett JM, Fann SA, Yost MJ. Purinergic signaling in early inflammatory events of the foreign body response: modulating extracellular ATP as an enabling technology for engineered implants and tissues. Tissue Eng Part B Rev (2014) 20(5):392-402. Epub 2014/01/16. doi: 10.1089/ten.TEB.2013.0554. PubMed PMID: 24279914.

60. Liu L, Das S, Losert W, Parent CA. mTORC2 regulates neutrophil chemotaxis in a cAMP- and 
RhoA-dependent fashion. Dev Cell (2010) 19(6):845-57. doi: 10.1016/j.devcel.2010.11.004. PubMed PMID: 21145500.

61. Chen Y, Corriden R, Inoue Y, Yip L, Hashiguchi N, Zinkernagel A, et al. ATP release guides neutrophil chemotaxis via P2Y2 and A3 receptors. Science (2006) 314(5806):1792-5. doi: 10.1126/science.1132559. PubMed PMID: 17170310.

62. Pruenster M, Kurz ARM, Chung K-J, Cao-Ehlker X, Bieber S, Nussbaum CF, et al. Extracellular MRP8/14 is a regulator of $\beta 2$ integrin-dependent neutrophil slow rolling and adhesion. Nat Commun (2015) 6:6915-. doi: 10.1038/ncomms7915. PubMed PMID: 25892652.

63. Yago T, Tsukamoto H, Liu Z, Wang Y, Thompson LF, McEver RP. Multi-Inhibitory Effects of A2A Adenosine Receptor Signaling on Neutrophil Adhesion Under Flow. J Immunol (2015) 195(8):3880-9. Epub 2015/09/09. doi: 10.4049/jimmunol.1500775. PubMed PMID: 26355151.

64. Borregaard N, Sørensen OE, Theilgaard-Mönch K. Neutrophil granules: a library of innate immunity proteins. Trends Immunol (2007) 28(8):340-5. Epub 2007/07/12. doi: 10.1016/j.it.2007.06.002. PubMed PMID: 17627888.

65. Larsen MT, Häger M, Glenthøj A, Asmar F, Clemmensen SN, Mora-Jensen H, et al. miRNA130a regulates C/EBP- $\varepsilon$ expression during granulopoiesis. Blood (2014) 123(7):1079-89. Epub 2014/01/07. doi: 10.1182/blood-2013-08-523233. PubMed PMID: 24398327.

66. Chen Y, Hashiguchi N, Yip L, Junger WG. Hypertonic saline enhances neutrophil elastase release through activation of P2 and A3 receptors. Am J Physiol Cell Physiol (2006) 290(4):C1051C9. Epub 2005/11/09. doi: 10.1152/ajpcell.00216.2005. PubMed PMID: 16282197.

67. Chacko BK, Wall SB, Kramer PA, Ravi S, Mitchell T, Johnson MS, et al. Pleiotropic effects of 4hydroxynonenal on oxidative burst and phagocytosis in neutrophils. Redox Biol (2016) 9:57-66. Epub 2016/06/23. doi: 10.1016/j.redox.2016.06.003. PubMed PMID: 27393890.

68. van der Hoeven D, Wan TC, Gizewski ET, Kreckler LM, Maas JE, Van Orman J, et al. A role for the low-affinity $A 2 B$ adenosine receptor in regulating superoxide generation by murine neutrophils. J Pharmacol Exp Ther (2011) 338(3):1004-12. Epub 2011/06/21. doi: 10.1124/jpet.111.181792. PubMed PMID: 21693629.

69. Lahoz-Beneytez J, Elemans M, Zhang Y, Ahmed R, Salam A, Block M, et al. Human neutrophil kinetics: modeling of stable isotope labeling data supports short blood neutrophil half-lives. Blood (2016) 127(26):3431-8. Epub 2016/05/02. doi: 10.1182/blood-2016-03-700336. PubMed PMID: 27136946.

70. Le Duc D, Schulz A, Lede V, Schulze A, Thor D, Brüser A, et al. P2Y Receptors in Immune Response and Inflammation. Adv Immunol (2017) 136:85-121. Epub 2017/06/10. doi: 10.1016/bs.ai.2017.05.006. PubMed PMID: 28950952.

71. Colgan SP, Eltzschig HK. Adenosine and hypoxia-inducible factor signaling in intestinal injury and recovery. Annu Rev Physiol (2012) 74:153-75. Epub 2011/11/19. doi: 10.1146/annurevphysiol-020911-153230. PubMed PMID: 21942704.

72. Zhang C, Shu W, Zhou G, Lin J, Chu F, Wu H, et al. Anti-TNF- $\alpha$ Therapy Suppresses Proinflammatory Activities of Mucosal Neutrophils in Inflammatory Bowel Disease. Mediators Inflamm (2018) 2018:3021863-. doi: 10.1155/2018/3021863. PubMed PMID: 30595666.

73. Deaglio S, Dwyer KM, Gao W, Friedman D, Usheva A, Erat A, et al. Adenosine generation catalyzed by CD39 and CD73 expressed on regulatory T cells mediates immune suppression. $J$ Exp Med (2007) 204(6):1257-65. Epub 2007/05/14. doi: 10.1084/jem.20062512. PubMed PMID: 17502665. 
74. Cesaro A, Brest P, Hofman V, Hébuterne X, Wildman S, Ferrua B, et al. Amplification loop of the inflammatory process is induced by P2X7R activation in intestinal epithelial cells in response to neutrophil transepithelial migration. Am J Physiol Gastrointest Liver Physiol (2010) 299(1):G32G42. Epub 2010/02/25. doi: 10.1152/ajpgi.00282.2009. PubMed PMID: 20185692.

75. Friedman DJ, Künzli BM, A-Rahim YI, Sevigny J, Berberat PO, Enjyoji K, et al. From the Cover: CD39 deletion exacerbates experimental murine colitis and human polymorphisms increase susceptibility to inflammatory bowel disease. Proc Natl Acad Sci U S A (2009) 106(39):16788-93. Epub 2009/09/28. doi: 10.1073/pnas.0902869106. PubMed PMID: 19805374.

76. Louis NA, Robinson AM, MacManus CF, Karhausen J, Scully M, Colgan SP. Control of IFN alphaA by CD73: implications for mucosal inflammation. J Immuno/ (2008) 180(6):4246-55. doi: 10.4049/jimmunol.180.6.4246. PubMed PMID: 18322237.

77. Nuka E, Ohnishi K, Terao J, Kawai Y. ATP/P2X7 receptor signaling as a potential antiinflammatory target of natural polyphenols. PLOS One (2018) 13(9):e0204229-e. doi: 10.1371/journal.pone.0204229. PubMed PMID: 30248132.

78. Sitkovsky M, Lukashev D. Regulation of immune cells by local-tissue oxygen tension: HIF1 alpha and adenosine receptors. Nat Rev Immunol (2005) 5(9):712-21. doi: 10.1038/nri1685. PubMed PMID: 16110315.

79. Naganuma M, Wiznerowicz EB, Lappas CM, Linden J, Worthington MT, Ernst PB. Cutting edge: Critical role for A2A adenosine receptors in the T cell-mediated regulation of colitis. J Immunol (2006) 177(5):2765-9. doi: 10.4049/jimmunol.177.5.2765. PubMed PMID: 16920910.

80. Schmidt GA. Managing Acute Lung Injury. Clin Chest Med (2016) 37(4):647-58. Epub 2016/09/09. doi: 10.1016/j.ccm.2016.07.005. PubMed PMID: 27842745.

81. Grudzinska FS, Sapey E. Friend or foe? The dual role of neutrophils in lung injury and repair. Thorax (2018) 73(4):305-7. Epub 2018/01/29. doi: 10.1136/thoraxjnl-2017-211253. PubMed PMID: 29382796.

82. Shah D, Romero F, Stafstrom W, Duong M, Summer R. Extracellular ATP mediates the late phase of neutrophil recruitment to the lung in murine models of acute lung injury. Am J Physiol Lung Cel/ Mol Physio/(2014) 306(2):L152-L61. Epub 2013/11/27. doi: 10.1152/ajplung.00229.2013. PubMed PMID: 24285266.

83. Cicko S, Köhler TC, Ayata CK, Müller T, Ehrat N, Meyer A, et al. Extracellular ATP is a danger signal activating P2X7 receptor in a LPS mediated inflammation (ARDS/ALI). Oncotarget (2018) 9(55):30635-48. doi: 10.18632/oncotarget.25761. PubMed PMID: 30093975.

84. Hildebrand D, Uhle F, Sahin D, Krauser U, Weigand MA, Heeg K. The Interplay of Notch Signaling and STAT3 in TLR-Activated Human Primary Monocytes. Front Cell Infect Microbiol (2018) 8:241-. doi: 10.3389/fcimb.2018.00241. PubMed PMID: 30042932.

85. Wang TTY, Pham Q, Kim YS. Elucidating the Role of CD84 and AHR in Modulation of LPSInduced Cytokines Production by Cruciferous Vegetable-Derived Compounds Indole-3-Carbinol and 3,3'-Diindolylmethane. Int J Mol Sci (2018) 19(2):339. doi: 10.3390/ijms19020339. PubMed PMID: 29364159.

86. Mishra A, Guo Y, Zhang L, More S, Weng T, Chintagari NR, et al. A Critical Role for P2X7 Receptor-Induced VCAM-1 Shedding and Neutrophil Infiltration during Acute Lung Injury. J Immunol (2016) 197(7):2828-37. Epub 2016/08/24. doi: 10.4049/jimmunol.1501041. PubMed PMID: 27559050.

87. Bomfim CCB, Amaral EP, Cassado ADA, Salles ÉM, do Nascimento RS, Lasunskaia E, et al. 
P2X7 Receptor in Bone Marrow-Derived Cells Aggravates Tuberculosis Caused by Hypervirulent Mycobacterium bovis. Front Immunol (2017) 8:435-. doi: 10.3389/fimmu.2017.00435. PubMed PMID: 28450867.

88. Di Virgilio F, Dal Ben D, Sarti AC, Giuliani AL, Falzoni S. The P2X7 Receptor in Infection and Inflammation. Immunity (2017) 47(1):15-31. doi: 10.1016/j.immuni.2017.06.020. PubMed PMID: 28723547.

89. Liverani E, Rico MC, Tsygankov AY, Kilpatrick LE, Kunapuli SP. P2Y12 Receptor Modulates Sepsis-Induced Inflammation. Arterioscler Thromb Vasc Biol (2016) 36(5):961-71. Epub 2016/04/07. doi: 10.1161/ATVBAHA.116.307401. PubMed PMID: 27055904.

90. Rahman M, Gustafsson D, Wang Y, Thorlacius H, Braun Ö̈. Ticagrelor reduces neutrophil recruitment and lung damage in abdominal sepsis. Platelets (2014) 25(4):257-63. Epub 2013/07/15 doi: 10.3109/09537104.2013.809520. PubMed PMID: 23855479.

91. Rabinovich-Nikitin I, Kirshenbaum LA. Exercise-Induced Myonectin Protects Against Ischemia-Reperfusion Injury. Circ Res (2018) 123(12):1264-6. doi: 10.1161/CIRCRESAHA.118.314129. PubMed PMID: 30566057.

92. Tang J, Zhuang S. Histone acetylation and DNA methylation in ischemia/reperfusion injury. Clin Sci (Lond) (2019) 133(4):597-609. doi: 10.1042/CS20180465. PubMed PMID: 30804072.

93. Hausenloy DJ, Yellon DM. Myocardial ischemia-reperfusion injury: a neglected therapeutic target. J Clin Invest (2013) 123(1):92-100. Epub 2013/01/02. doi: 10.1172/JCI62874. PubMed PMID: 23281415.

94. Li K, Gong X, Kuang G, Jiang R, Wan J, Wang B. Sesamin protects against renal ischemia reperfusion injury by promoting CD39-adenosine-A2AR signal pathway in mice. Am J Trans/ Res (2016) 8(5):2245-54. PubMed PMID: 27347331.

95. Mulloy DP, Sharma AK, Fernandez LG, Zhao Y, Lau CL, Kron IL, et al. Adenosine A3 receptor activation attenuates lung ischemia-reperfusion injury. Ann Thorac Surg (2013) 95(5):1762-7. Epub 2013/03/28. doi: 10.1016/j.athoracsur.2013.01.059. PubMed PMID: 23541429.

96. Koeppen M, Harter PN, Bonney S, Bonney M, Reithel S, Zachskorn C, et al. Adora2b signaling on bone marrow derived cells dampens myocardial ischemia-reperfusion injury. Anesthesiology (2012) 116(6):1245-57. doi: 10.1097/ALN.0b013e318255793c. PubMed PMID: 22531331.

97. Koo TY, Lee J-G, Yan J-J, Jang JY, Ju KD, Han M, et al. The P2X7 receptor antagonist, oxidized adenosine triphosphate, ameliorates renal ischemia-reperfusion injury by expansion of regulatory T cells. Kidney Int (2017) 92(2):415-31. Epub 2017/04/08. doi: 10.1016/j.kint.2017.01.031. PubMed PMID: 28396117.

98. Wang X, Chen D. Purinergic Regulation of Neutrophil Function. Front Immuno/ (2018) 9:399-. doi: 10.3389/fimmu.2018.00399. PubMed PMID: 29545806. 


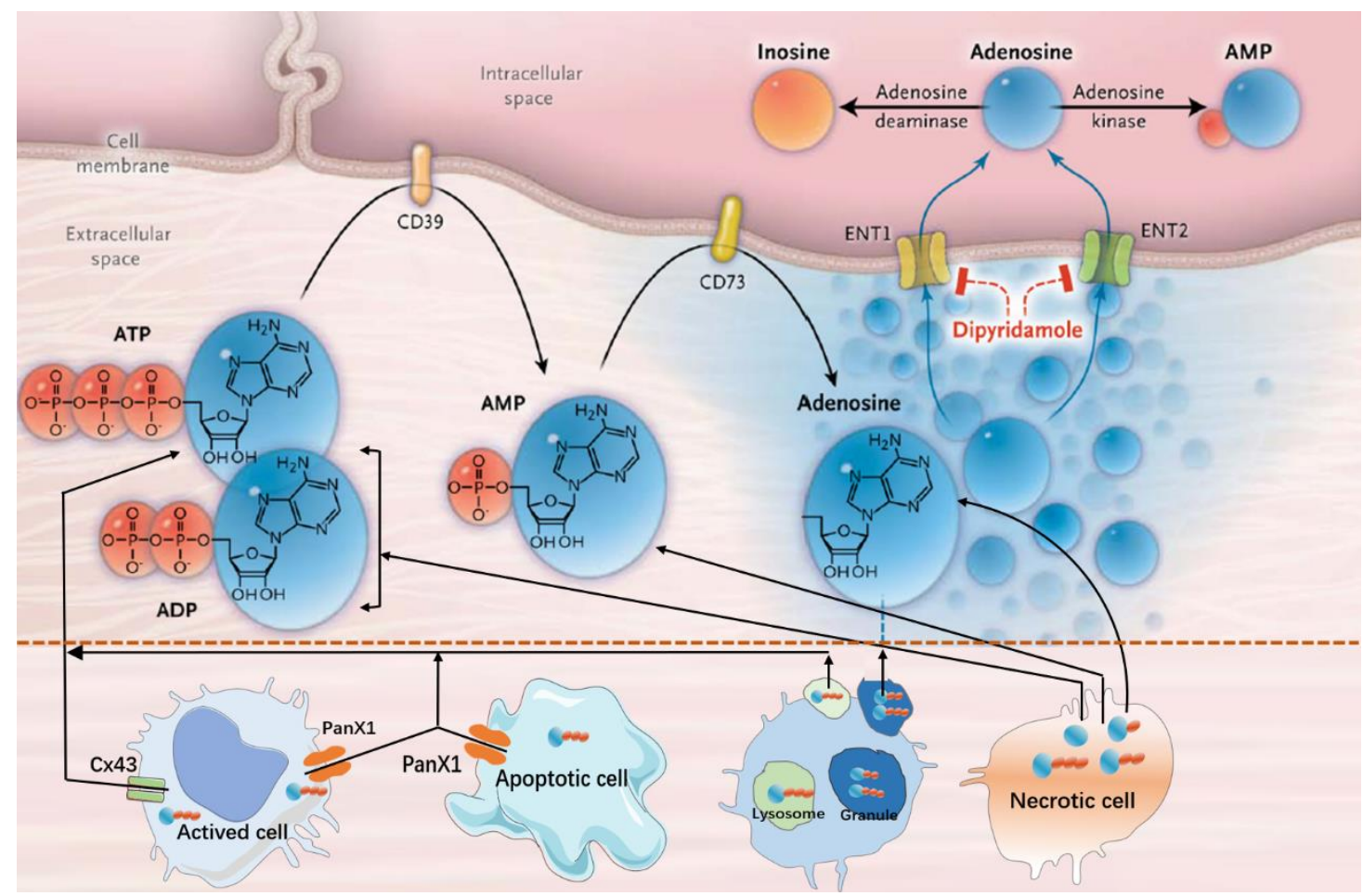

Figure 1 Purinergic signal and release of extracellular ATP and ADO.

Under inflammatory conditions, purinergic signal is mainly derived from precursor nucleotides ATP and ADP are converted to AMP, through extracellular nucleoside diphosphate hydrolase 1 (CD39) enzyme activity, and then AMP is converted to adenosine through extracellular-5'nucleotidase (CD73). In the process of apoptosis, Panx1 is cleaved by apoptotic executive enzymes (caspase3 and 7) to produce a truncated activation subunit, which regulates the ATP release of apoptotic cells. In some pathological conditions, the release of extracellular ATP is finely regulated by the diffusion of semi-tubules of connexin 43 (Cx43) or connexin 1 (Panx1) and the exocytosis of ATP-rich vesicles such as granules and lysosomes. Under extreme conditions, cell necrosis releases a large amount of ATP from the intracellular storage pool. 